\title{
Factors of quality of care and their association with smartphone based PHR adoption in South Korean hospitals
}

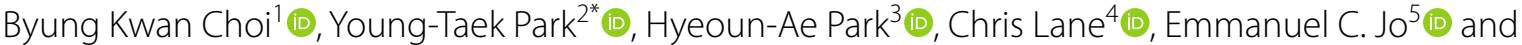 \\ Sunghong Kang ${ }^{6}$ (D)
}

\begin{abstract}
Background: Healthcare organizations have begun to adopt personal health records (PHR) systems to engage patients, but little is known about factors associated with the adoption of PHR systems at an organizational level. The objective of this study is to investigate factors associated with healthcare organizations' adoption of PHR systems in South Korea.

Methods: The units of analysis were hospitals with more than 100 beds. Study data of 313 hospitals were collected from May 1 to June 30, 2020. The PHR adoption status for each hospital was collected from PHR vendors and online searches. Adoption was then confirmed by downloading the hospital's PHR app and the PHR app was examined to ascertain its available functions. One major outcome variable was PHR adoption status at hospital level. Data were analysed by logistic regressions using SAS 9.4 version.
\end{abstract}

Results: Out of 313 hospitals, 103 (32.9\%) hospitals adopted PHR systems. The nurse-patient ratio was significantly associated with PHR adoption (OR 0.758; 0.624 to 0.920, $p=0.005$ ). The number of health information management staff was associated with PHR adoption (OR 1.622; 1.228 to 2.141, $\mathrm{p}=0.001$ ). The number of CTs was positively associated with PHR adoption (OR 5.346; 1.962 to $14.568, p=0.001$ ). Among the hospital characteristics, the number of beds was significantly related with PHR adoption in the model of standard of nursing care (OR 1.003; 1.001 to 1.005, $\mathrm{p}<0.001)$, HIM staff (OR 1.004; 1.002 to 1.006, $\mathrm{p}<0.001$ ), and technological infrastructure (OR 1.050; 1.003 to 1.006, $\mathrm{p}<0.001)$.

Conclusions: One-third of study hospitals had adopted PHR systems. Standard of nursing care as well as information technology infrastructure in terms of human resources for health information management and advanced technologies were significantly associated with adoption of PHR systems. A favourable environment for adopting new technologies in general may be associated with the adoption and use of PHR systems.

Keywords: Personal health records, Electronic medical records, Electronic health records, Information systems, Quality of care

*Correspondence: youngtaek.park@gmail.com

${ }^{2}$ HIRA Research Institute, Health Insurance Review and Assessment Service (HIRA), 60 Hyeoksin-ro, HIRA building 9th floor, Wonju-si, Gangwon-do 26465, Republic of Korea

Full list of author information is available at the end of the article

\section{Background}

Personal health record (PHR) systems are being introduced into healthcare organisations in recent years [1, 2]. Healthcare organisations have allowed their patients to view some information from their electronic medical records such as history of visits, medications, and 
laboratory test results through web-based programs or mobile applications [3, 4]. Some hospitals even allow their patients to enter their vital signs and symptoms to the system or make appointments for their next visits through mobile applications [5-7].

According to the Office of the National Coordinator for Health Information Technology in the United States, a PHR system is "an electronic application through which patients can maintain and manage their health information (and that of others for whom they are authorised) in a private, secure, and confidential environment." [8] However, there has been no universally accepted definition of a PHR [9] and other terms such as patient portal [10], mobile or $m$-health for patients have been used interchangeably with PHR $[11,12]$.

Various factors such as improved patient-provider communication, patient empowerment and involvement, provider's financial burden on PHR investments, and privacy and security issues are known to be associated with PHR system adoption [3, 5, 9]. In South Korea with the uniform pricing of health care services under the national health insurance program, the main incentives for patients to revisit healthcare facilities are the provision of high quality care or customer services. There are a large number of hospitals competing for patients, and at the same time, potential patients are not constrained by enrolment or insurance schemes to use particular health providers, and do not need to be referred to hospitals by primary care physicians. Potential patients are free to choose hospitals on the basis of their own experiences or their impressions of the quality of care in different hospitals [13-15]. Consequently, hospitals are marketed directly to potential patients by vigorously advertising how well patients are looked after and how advanced the hospital infrastructure is.

When patients think about visiting medical facilities, they tend to put a high priority on the quality of care [16-18]. Quality of care has a particularly strong effect on patients' next visits in Korea because they can go to any medical facility they choose $[13,14]$. Patients can even choose any tertiary hospital after getting a referral from a primary care provider. Hence medical facilities try their best to keep their patients, to maximise their profits in a competitive environment.

PHR systems have various advantages for both healthcare organisations and patients in terms of high quality of care and customer services $[19,20]$. Thus, there are some possibilities that hospitals dedicating more attention to high quality of care are more likely to adopt PHR systems.

Managing health information is very important to achieve better quality of care [21]. However, the decision for a hospital to invest in a new technology depends on the current status of its human resources and technology infrastructure. It would be easy for hospitals with welldeveloped resources to decide on additional inputs or financial investments in information technology to improve quality of care and customer service. However, it would be more challenging for hospitals lacking such advanced infrastructure to choose to adopt the new technology because the effort and resources are too great.

Thus, hospitals that are active in improving the quality of care and customer service, and that have well-developed information technology infrastructure are expected to be early adopters of PHR systems. This implies that there may be a positive relationship between adoption of PHR systems and factors such as quality care activities, status of information technology infrastructure or advanced medical diagnostic technologies and equipment.

There have been few studies on the relationship between the adoption of PHR systems and these factors and most of studies were conducted at individual level and dealing with general topics such as various information technologies even if they were studied at organizational level $[19,22]$. According to the Institute of Medicine's report “To Err is Human", most medical errors come from internal system failure, which can be remedied by implementing IT systems such as mandatory error reporting systems [23]. Several comprehensive review studies have found that various health information technologies such as computerized physician order entry systems and clinical decision support systems critically affect quality of care such as patient safety [23-26].

Several empirical studies indirectly suggest some possibility of positive relationship between adoption of PHR systems and quality care activities including information technology infrastructure or advanced medical diagnostic equipment. Symons et al. verified that hospitals adopting various IT applications had better quality of care with respect to gastrointestinal haemorrhage and acute myocardial infarction [27]. PHR systems in connection with quality of healthcare delivery have been recommended [28]. Healthcare delivery organizations have sought to adopt various strategies to promote patient and provider uptake of PHR systems [22]. According to a recent study, hospitals with a higher level of technological infrastructure adopted more electronic medical record systems [29]. Lack of information technology infrastructure has been mentioned as one of the impediments of PHR system adoption [30]. However, most previous studies on PHR adoption have focused on individual patients or primary care providers rather than organisations [31-33].

Little is known about PHR system adoption at organisational levels based on real world data. Hospitals in Korea run independently as medical providers. Given that PHR adoption with hospitals as units of analysis has 
rarely been studied internationally, findings from Korean healthcare can provide new insights and clues into how hospitals adopt IT and which hospitals are earlier adopters.

With this background, the objective of this study is to investigate the factors associated with the PHR system adoption by Korean hospitals. This study used secondary health insurance administrative data and empirically collected data from PHR vendors to focus on hospitals at the organisational level. The findings of this study will provide a basis for policy-makers to promote the introduction of various information technologies into healthcare services. However, this study does not attempt to examine the causality of adoption of PHR systems, but rather it explores the relationship between PHR adoption and factors such as quality of care activities and technological infrastructure of the hospitals.

\section{Methods}

\section{Study setting}

In Korea, there are three categories of hospitals based on the Medical Law and the National Health Insurance Law of Korea: tertiary hospitals, general hospitals, and hospitals (hereafter "small hospitals"). Tertiary hospitals have 20 or more medical specialties and provide training programs for these medical specialists. All of these tertiary hospitals are affiliated to medical schools. General hospitals should have seven or more medical specialties for hospitals with beds between 100 and 300, or nine or more medical specialties for hospitals with 300 or more beds. Small hospitals have beds between 30 and 100. The number of beds is closely related with independent variables of the study, namely characteristics of the hospitals. Thus, we standardized the independent variables with the number of beds and used the standardized variables in the analysis.

\section{Study design and data sources}

The time horizon of the study is cross-sectional and the units of analysis are hospitals. There were a total of 273 general hospitals and 43 tertiary hospitals with more than 100 beds as of March 31, 2019 in Korea. We studied PHR systems in all of these hospitals from May 1 to June 30, 2020. Rather than sampling study hospitals, we included all hospitals to improve the statistical power and generalization of the study findings.

In this study "PHR" is defined as software that allows patients to access their electronic medical records in healthcare organisations through smartphones or mobile phones with the functionalities of booking, scheduling appointments, viewing or confirming prescription status, and viewing test results. PHR systems in this study are limited to mobile applications. The functions and features of the PHR systems are similar to those ones presented in previous studies [1,34, 35].

Figure 1 shows a flow diagram of selecting study hospitals and collecting study variables. The list of study hospitals (including each hospital's name and address) was extracted from the public domain website, "Healthcare Big Data Hub" (https://opendata.hira.or.kr/op/opc/selec tOpenDataList.do), run by the Health Insurance Review \& Assessment Services (HIRA). A researcher with a medical degree investigated the PHR adoption status of study hospitals. With the hospital lists, the researcher first conducted a market search for PHR system vendors, developers, their products, and the functionalities of the products. IT vendor companies developing PHR systems provide commercialised and customised PHR products to healthcare organizations. Thus, it was possible to obtain the list of hospitals adopting PHR systems from the vendors. For example, Lemon Healthcare, Ltd, in Korea has developed standardised mobile PHR platforms and provided them to more than 40 large hospitals.

We collected PHR adoption status from PHR vendors and online searches. First, we cross-checked the vendors' lists of hospitals by downloading each hospital's PHR app from Google Play and the Apple Store. Then we checked the functions of its PHR system to confirm its adoption status. Second, the researcher entered the names of the

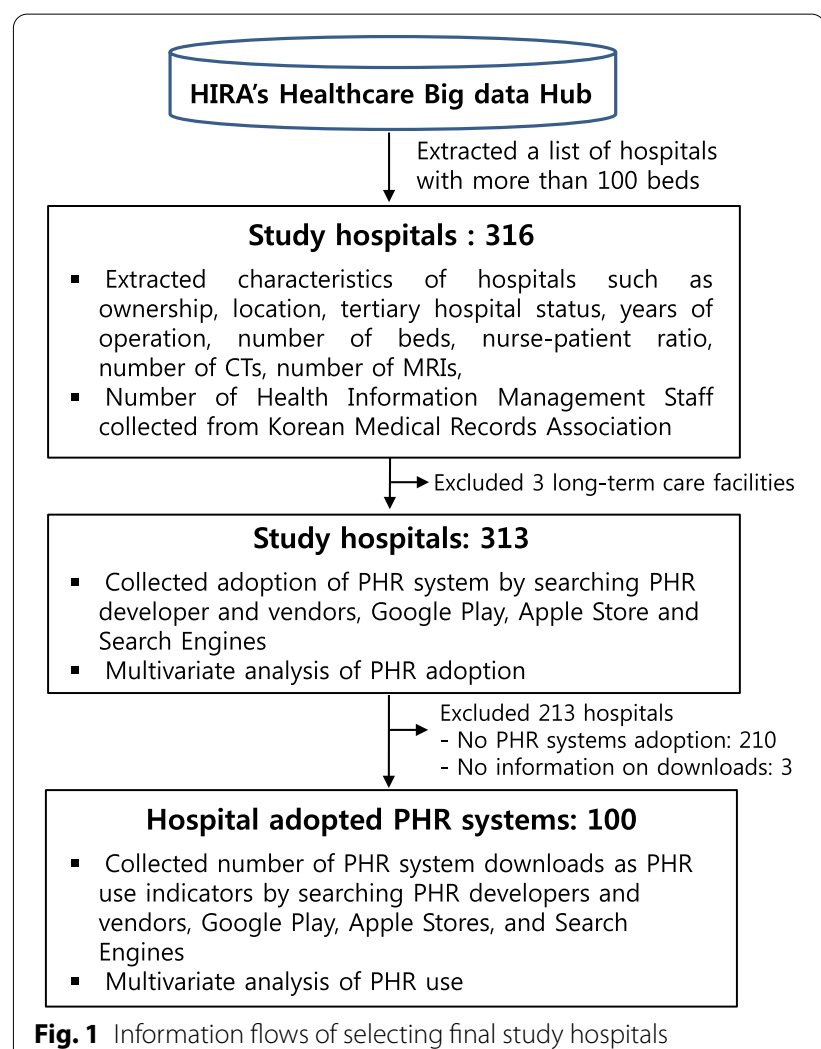


remaining hospitals (which were not in the vendor's lists) into a search engine one by one and identified each hospital's PHR adoption status. The search engines used were Google (google.co.kr) and a Korean search engine called NAVER (Naver.com). If it was found that a hospital had adopted a PHR system, we confirmed the adoption status by downloading its PHR app, and then recorded the functions of its PHR system.

The data collection procedure and collected functions of PHR systems are presented more in detail in a paper published by the authors [36].

The number of health information management staff (or employees) in each hospital was collected from the Korean Medical Records Association. Finally, the data were merged with the HIRA's Healthcare Big Data Hub portal data and PHR system study data. The ethical approval for this study was obtained from the Institutional Review Board (IRB) of Pusan National University (IRB No. H-2004-026-090) on April 28, 2020. Pusan National University Hospital provided the funding for the study and was also involved in the design of the study, data collection, and revised the paper.

\section{Outcome and independent variables}

The outcome variable is adoption of mobile-based PHR systems at hospitals. Mobile-based PHR system adoption (hereafter "PHR system adoption" or "PHR adoption") was measured by determining whether hospitals adopted mobile PHR systems. This study included mobile PHR systems being operated on either Android or iPhone operating systems.

Three main independent variables are standard of nursing care, infrastructure capacity in terms of human resources, and advanced diagnostic technologies. Standard of nursing, a proxy variable for quality of care, was measured by the ratio of patients to nurses (nurse-patient ratio). A lower figure for the nurse-patient ratio means a higher standard of nursing care because each nurse cares for fewer patients. HIRA has introduced an incentive program for the nurse-patient ratios. There are seven grades for measuring the standard of nursing care. In the case of general hospitals, 1st grade refers to nurse-patient ratios under 2.5, 2nd grade at least 2.5 but less than 3.0, 3rd to at least 3.0 but less than 3.5, 4th to at least 3.5 but less than 4.0, 5 th to at least 4.0 but less than $4.5,6$ th to at least 4.5 but less than 6.0, and 7th grade to ratios of 6.0 and over. HIRA applies different reimbursement schedules to hospitals depending on these grades. This study used the same seven grades of standard of nursing care as used by HIRA. Hospital infrastructure capacity refers to resources such as buildings, human resources, equipment, IT, and processes [37]. We measured infrastructure capacity in terms of human resources and advanced diagnostic medical equipment. The former is measured by the number of health information management (HIM) staff holding a medical recorder licence and the latter is measured by the number of computerised tomographies (CTs) and magnetic resonance imaging scans (MRIs).

The remaining independent variables were extracted from publicly available open data sets in the "Healthcare Big Data Hub" run by the HIRA. The list of independent variables was affected by availability and collectability of the data. These variables are types of ownership (private versus public), location of facility (mega-metropolitan or not), types of hospitals (tertiary or general hospitals), number of years of operation, and size of hospital measured by the number of beds, which were examined in similar studies regarding PHR and adoption of electronic health record systems in the past [29, 36, 38, 39]. They were included to control the effect of confounding variables. Mega-metropolitan location is an administrative district with more than one million residents. All these data were measured as of March 31, 2020.

\section{Statistical analysis}

This study first analysed the general characteristics of the study hospitals by PHR adoption status (no PHR adoption versus PHR adoption) using descriptive statistics. For comparing any two groups, t-tests were used for numeric measures and Chi-square tests for categorical measures.

Correlations among the independent variables were examined before a multivariate analysis. Spearman correlation was used for variables that do not follow a normal distribution. We found that the number of beds was significantly associated with the independent variables. Thus, we standardised the independent variables by the number of beds. The standardised variables were HIM staff per 100 beds, number of CTs per 100 beds, and number of MRIs per 100 beds. There was no statistically significant correlation among independent variables after standardisation by the number of beds. These adjusted figures were used in the multivariate analysis.

Logistic regression was used to investigate the relationship between PHR adoption and hospital characteristics, since the outcome variable of adopting or not adopting a PHR system is binary. SAS version 9.4 was used for the data analysis.

\section{Results}

General characteristics of the study hospitals General characteristics of study hospitals regarding PHR adoption

Table 1 presents the general characteristics of the study hospitals. Among these hospitals, 32.9\% adopted PHR systems. Hospitals that adopted PHR systems 
Table 1 General characteristics of the study hospitals regarding PHR adoption

\begin{tabular}{|c|c|c|c|c|}
\hline \multirow[t]{2}{*}{ Variables } & \multicolumn{3}{|c|}{ Status of PHR adoption } & \multirow[t]{2}{*}{$\mathrm{p}$-value } \\
\hline & $\begin{array}{l}\text { No PHR adoption } \\
(\mathrm{N}=210)\end{array}$ & $\begin{array}{l}\text { PHR adoption } \\
(\mathrm{N}=103)^{* * * *}\end{array}$ & $\begin{array}{l}\text { Total } \\
(\mathrm{N}=313)\end{array}$ & \\
\hline$\%$ & 100.0 & 100.0 & 100.0 & - \\
\hline Ownership (\%) & & & & 0.7012 \\
\hline Private & 81.4 & 79.6 & 80.8 & \\
\hline Public & 18.6 & 20.4 & 19.2 & \\
\hline Location (\%) & & & & 0.0004 \\
\hline Mega-metropolitan cities & 39.1 & 60.2 & 46.0 & \\
\hline The others & 60.9 & 39.8 & 54.0 & \\
\hline Tertiary hospitals (\%) & & & & $<0.0001$ \\
\hline Yes & 4.8 & 32.0 & 13.7 & \\
\hline No & 95.2 & 68.0 & 86.3 & \\
\hline Years of operation (std.*) & $26.5(12.4)$ & $29.8(15.5)$ & $27.6(13.5)$ & 0.0603 \\
\hline Number of beds (std.) & $326.8(187.2)$ & $641.9(427.2)$ & $430.4(324.2)$ & $<0.0001$ \\
\hline Nurse-patient ratio $(\mathrm{std})^{* *}$ & $4.3(1.9)$ & $2.5(1.7)$ & $3.7(2.0)$ & $<0.0001$ \\
\hline Number of HIM staff (std.) & $4.9(5.1)$ & $14.2(12.6)$ & $7.9(9.4)$ & $<0.0001$ \\
\hline Number of CTs (std) & $2.1(1.5)$ & $4.7(3.4)$ & $3.0(2.6)$ & $<0.0001$ \\
\hline Number of MRIs (std) & $1.5(0.8)$ & $2.7(2.3)$ & $1.9(1.6)$ & $<0.0001$ \\
\hline
\end{tabular}

*std: Standard deviation, ${ }^{* *}$ Seven grades based on nurse-patient ratios (see text), ***Unit: 10 thousand, ${ }^{* * *} 3$ cases were only iPhone operating systems

showed statistically significant differences on location (mega-metropolitan cities), tertiary hospitals, low nurse-patient ratio (meaning a high number of nurses available per patient), and high numbers of beds, CTs, and MRIs.

\section{Correlation of study variables}

Table 2 shows the correlation matrix among the independent variables after adjusting by the number of beds. No high correlation was observed among the independent variables.

Table 2 Correlation** among independent variables of study hospitals ( $N=313$ )

\begin{tabular}{|c|c|c|c|c|c|c|c|c|c|}
\hline Variables & 1 & 2 & 3 & 4 & 5 & 6 & 7 & 8 & 9 \\
\hline \multirow[t]{2}{*}{ 1. Ownership* } & 1.000 & 0.124 & -0.089 & -0.182 & -0.030 & 0.024 & -0.023 & 0.025 & 0.050 \\
\hline & & 0.0285 & 0.1178 & 0.0012 & 0.5997 & 0.6689 & 0.683 & 0.6633 & 0.3734 \\
\hline \multirow[t]{2}{*}{ 2. Location* } & & 1.000 & 0.172 & 0.087 & 0.102 & -0.332 & 0.231 & 0.089 & 0.016 \\
\hline & & & 0.0023 & 0.1247 & 0.0714 & $<.0001$ & $<.0001$ & 0.1154 & 0.7727 \\
\hline \multirow[t]{2}{*}{ 3. Tertiary* hospitals } & & & 1.000 & 0.232 & 0.580 & -0.454 & 0.284 & 0.059 & -0.233 \\
\hline & & & & $<.0001$ & $<.0001$ & $<.0001$ & $<.0001$ & 0.2976 & $<.0001$ \\
\hline \multirow[t]{2}{*}{ 4. Years of operation } & & & & 1.000 & 0.195 & -0.162 & 0.164 & -0.091 & -0.238 \\
\hline & & & & & 0.0005 & 0.004 & 0.0036 & 0.1092 & $<.0001$ \\
\hline \multirow[t]{2}{*}{ 5. Number of beds } & & & & & 1.000 & -0.603 & 0.360 & 0.016 & -0.478 \\
\hline & & & & & & $<.0001$ & $<.0001$ & 0.7771 & $<.0001$ \\
\hline \multirow[t]{2}{*}{ 6. Nurse- patient ratio } & & & & & & 1.000 & -0.453 & -0.233 & 0.122 \\
\hline & & & & & & & $<.0001$ & $<.0001$ & 0.0308 \\
\hline \multirow[t]{2}{*}{ 7. HIM staff*** } & & & & & & & 1.000 & 0.286 & -0.015 \\
\hline & & & & & & & & $<.0001$ & 0.7874 \\
\hline \multirow[t]{2}{*}{ 8. Number of $C T s^{* * *}$} & & & & & & & & 1.000 & 0.336 \\
\hline & & & & & & & & & $<.0001$ \\
\hline 9. Number of MRIs*** & & & & & & & & & 1.000 \\
\hline
\end{tabular}

*Binary variables were coded as 0 versus 1 such as no 1 (Private hospitals as 1,), 2 (Mega-metro cities as 1), 3 (Tertiary hospital as 1). **Spearman correlation. ***Variables 7-9 were standardised by the number of beds (each variable/bed*100) 


\section{.Factors associated with adoption and use of PHR Standard of nursing care}

Table 3 shows the relationship between adoption and use of PHR systems with standard of nursing care. Interestingly, the nurse-patient ratio was significantly associated with the adoption of PHR systems after controlling for the hospital characteristics. The odds of adopting a PHR system decreases by $24.2 \%$ as the nurse-patient ratio increases (meaning that standard of nursing care deteriorated because a nurse had to take care of more patients) for one unit (OR 0.758; 0.624 to $0.920, \mathrm{p}=0.005$ ).

\section{HIM staff}

Table 4 presents the association between adoption of PHR systems with HIM manpower in hospitals. Interestingly, the number of staff working for health information management was significantly associated with PHR adoption after controlling for the hospital characteristics. The odds of adopting a PHR system increased by $62.2 \%$ (OR $1.622 ; 1.28$ to $2.141, \mathrm{p}=0.001$ ) as the number of staff in health information management increased by one unit after controlling for the hospital characteristics.

\section{Technological infrastructure: CTs and MRIs}

Table 5 shows the analysis results on the relationship between adoption of PHR systems with technological infrastructure in terms of CTs and MRIs. Technological infrastructure in terms of CTs and MRIs was measured by the number of CTs and MRIs per 100 beds, respectively. The number of CTs was significantly associated with PHR system adoption after controlling for the hospital characteristics (OR 5.346; 1.962 to $14.568, \mathrm{p}=0.001$ ).

Table 3 Standard of nursing care as a factor associated with PHR adoption

\begin{tabular}{|c|c|c|c|c|}
\hline \multirow[t]{3}{*}{ Variables } & \multicolumn{4}{|c|}{ Adoption $(\mathrm{N}=313)$} \\
\hline & \multirow[t]{2}{*}{ OR } & \multicolumn{2}{|c|}{$95 \% \mathrm{Cl}$} & \multirow[t]{2}{*}{ p-value } \\
\hline & & LL & UL & \\
\hline Private ownership (Ref = Public) & 1.048 & 0.494 & 2.224 & 0.903 \\
\hline $\begin{array}{l}\text { Mega-metropolitan city location } \\
\text { (Ref = The others) }\end{array}$ & 1.589 & 0.880 & 2.868 & 0.124 \\
\hline Tertiary hospital (Ref = The others) & 0.848 & 0.272 & 2.639 & 0.776 \\
\hline Years of operation & 0.950 & 0.975 & 1.016 & 0.663 \\
\hline Number of beds & 1.003 & 1.001 & 1.005 & $<0.001$ \\
\hline Nurse-patient ratio & 0.758 & 0.624 & 0.920 & 0.005 \\
\hline
\end{tabular}

Excluded three cases with iPhone operating systems because of no information on use

OR Odds ratio, CI Confidence Interval, LL Lower limit, UL Upper limit
Table 4 Number of HIM staff as a factor associated with PHR adoption

\begin{tabular}{|c|c|c|c|c|}
\hline \multirow[t]{3}{*}{ Variables } & \multicolumn{4}{|c|}{ Adoption $(\mathrm{N}=313)$} \\
\hline & \multirow[t]{2}{*}{ OR } & \multicolumn{2}{|c|}{$95 \% \mathrm{Cl}$} & \multirow[t]{2}{*}{ p-value } \\
\hline & & LL & UL & \\
\hline Private ownership (Ref=Public) & 1.071 & 0.945 & 2.318 & 0.862 \\
\hline $\begin{array}{l}\text { Mega-metropolitan city location } \\
\text { (Ref=The others) }\end{array}$ & 1.741 & 0.976 & 3.106 & 0.060 \\
\hline Tertiary hospital (Ref $=$ The others) & 0.772 & 0.246 & 2.426 & 0.658 \\
\hline Years of operation & 0.995 & 0.974 & 1.016 & 0.631 \\
\hline Number of beds & 1.004 & 1.002 & 1.006 & $<0.001$ \\
\hline HIM staff & 1.622 & 1.228 & 2.141 & 0.001 \\
\hline
\end{tabular}

Excluded three cases with iPhone operating systems because of no information on use

OR Odds ratio, CI Confidence Interval, LL Lower limit, UL Upper limit

\section{Discussion}

This study found that $32.9 \%$ of all hospitals with more than 100 beds in Korea adopted PHR systems. The standard of nursing care based on nurse-patient ratios and the numbers of CTs were significantly associated with both adoption of PHR systems. Hospitals with more HIM staff were significantly more likely to adopt PHR systems. Additionally, the number of beds was significantly associated with adoption.

The PHR adoption rate in this study (32.9\%) was slightly higher than that of a European Union study. According to a European study conducted in 2018, requesting appointments and prescription renewals via PHR of primary care clinics such as general practitioners was $24 \%$ and $22 \%$, respectively [40]. According to the

Table 5 Technological infrastructure-CTs and MRIs as factors associated with PHR adoption

\begin{tabular}{llllr}
\hline Variables & \multicolumn{3}{l}{ Adoption (N=313) } \\
\cline { 2 - 4 } & OR & $\mathbf{9 5 \%} \mathbf{C l}$ & \multirow{2}{*}{ p-value } \\
\cline { 3 - 4 } & & LL & UL & \\
\hline Private ownership (Ref=Public) & 1.077 & 0.502 & 2.309 & 0.849 \\
Mega-metropolitan city location & 2.007 & 1.136 & 3.547 & 0.017 \\
(Ref=The others) & & & & \\
Tertiary hospital (Ref=The others) & 0.692 & 0.220 & 2.179 & 0.529 \\
Years of operation & 0.997 & 0.975 & 1.018 & 0.754 \\
Number of beds & 1.050 & 1.003 & 1.006 & $<0.001$ \\
Number of CTs & 5.346 & 1.962 & 14.568 & 0.001 \\
Number of MRIs & 0.387 & 0.074 & 2.037 & 0.263 \\
\hline
\end{tabular}

Excluded three cases with iPhone operating systems because of no information on use

OR Odds ratio, CI Confidence Interval, LL Lower limit, UL Upper limit 
Health Information National Trends Survey, 92\% of participants indicated that they are interested in accessing to their health records via online personal health information, but the access rate was only $28 \%$ [10]. These findings suggest that mobile PHR systems have potential for high growth and a bright future.

For the relationship between standard of nursing care and adoption of PHR systems, it was found that hospitals with a low nurse-patient ratio would be more likely to adopt PHR systems. The findings of this study are similar to those of many previous studies showing that hospitals are adopting various information technologies in order to reduce medical errors and to improve quality of care $[21,27,28]$. At the micro level, it would be difficult to see the direct causal relationship between standard of nursing care with the adoption of PHR systems. However, from a broader organization's perspective, hospitals making efforts to improve the standard of nursing care would be more likely to exert efforts to improve the quality of care by introducing new technologies. Directors or chief executives of hospitals having a low nurse-patient ratio may have had better experiences than those of other hospitals and clinics regarding the benefits of information technologies. Those cumulative efforts of hospitals for a long period of time might result in a positive relationship between quality of care factor and adoption of PHR systems. This might account for the significant relationship between PHR adoption and quality of care efforts.

Regarding hospital infrastructure and PHR adoption, this study found that hospitals with advanced infrastructure in terms of technological and human resources were more likely to adopt PHR systems. The findings of this study are similar to the findings of previous studies that found that hospitals having full EMR systems or higher stages of EMR adoption models also have advanced technological infrastructure such as having a computerized physician order entry system, laboratory information system, picture archiving communication system, or information technology department, and more information technology staff $[29,41]$. Since the billing price to a patient for CTs is very high, it is beneficial to hospitals to manage patients' appointments or booking schedules for CTs through PHR systems that can continually provide information to patients. However, it is not clear that having more HIM staff led to greater adoption of PHR systems or adoption of PHR systems led to more hiring of HIM staff, even though there is a positive relationship between PHR adoption and the number of HIM staff.

This study has several limitations. First, the unit of analysis is not patients but hospitals. In order to understand why patients are interested in using PHR systems, it is necessary to study both PHR adoption of hospitals and use with the patients as study subjects. This study did not include any patient factors in the models. Second, this study used a cross-sectional design, and as such it could not examine the causality underlying why hospitals adopt PHR systems. Further study is needed to reach a conclusion about causality by linking some organizational theories with the research findings, using more accurate and complete data.

\section{Conclusion}

This study found that $32.9 \%$ of general and tertiary hospitals in Korea had adopted PHR systems. Hospital factors having a high standard of nursing care measured by the nurse-patient ratio, a large number of CTs, and number of beds were significantly associated with PHR adoption. A large number of HIM staff was also related with PHR system adoption. This study was conducted as an exploratory study with an intention to delve into the factors associated with PHR adoption, with the aim that health care consumers can derive more benefits from greater adoption of PHR systems.

\section{Abbreviations}

Cl: Confidence interval; CTs: Computed tomographies; HIM: Health Information Management; HIRA: The Health Insurance Review and Assessment Service; LL: Lower limit; MRI: Magnetic resonance imaging; OR: Odds ratio; PHRs: Personal health records; RR: Relative risk; UL: Upper limit.

\section{Acknowledgements}

We also deeply thank Dr. Dong Hwan Kim, M.D., Department of Neurosurgery, Pusan National University Hospital and College of Medicine, Korea, for conducting the PHR survey and giving us excellent comments.

\section{Authors' contributions}

BKC, SK, and YTP developed the concept for this study, designed the methodology, and collected data. BKC applied for and received the IRB approval and research grant from his university hospital. YTP and HAP conducted statistical analysis. YTP, HAP, CL, and ECJ participated in the interpretation of the analysis results. The manuscript was drafted by YTP, HAP, and CL. All six authors substantially contributed to revisions and have approved the final submitted version to be published. All six authors agreed to be accountable for every aspect of the work related to accuracy and integrity in terms of research methods, results, and research process. All authors read and approved the final manuscript

\section{Funding}

This study was supported for two years by a Pusan National University Research Grant.

\section{Availability of data and materials}

The datasets during and/or analysed during the current study are available from the corresponding author upon reasonable request.

\section{Declarations}

\section{Ethics approval and consent to participate}

Ethical approval for this study was obtained from the Institutional Review Board (IRB) of the Pusan National University (IRB No. H-2004-026-090) on April 28,2020 . No consent to participate was required for this study.

\section{Consent for publication}

Not applicable. 


\section{Competing interests}

The authors declare that they have no competing interests.

\section{Author details}

${ }^{1}$ Department of Neurosurgery, School of Medicine, Pusan National University, 2 Busandaehak-ro 63beon-gil, Geumjeong-gu, Busan 46241, Republic of Korea. ${ }^{2}$ HIRA Research Institute, Health Insurance Review and Assessment Service (HIRA), 60 Hyeoksin-ro, HIRA building 9th floor, Wonju-si, Gangwon-do 26465, Republic of Korea. ${ }^{3}$ College of Nursing, Seoul National University, 103 Daehak-ro, Jongno-gu, Seoul 03080, Republic of Korea. ${ }^{4}$ Analytics and Intelligence, Health Workforce, New Zealand Ministry of Health, 133 Molesworth St, Thorndon, Wellington 6011, New Zealand. ${ }^{5}$ School of Medicine, University of Auckland, 85 Park road, Grafton, Auckland 1023, New Zealand. ${ }^{6}$ Department of Health Policy and Management, Inje University, 197 Inje-ro, Gimhae-si, Gyeongsangnam-do 50834, Republic of Korea.

\section{Received: 17 September 2020 Accepted: 19 October 2021} Published online: 29 October 2021

\section{References}

1. Jung SY, Lee K, Hwang H, Yoo S, Baek HY, Kim J. Support for sustainable use of personal health records: understanding the needs of users as a first step towards patient-driven mobile health. JMIR Mhealth Uhealth. 2017:5(2):e19.

2. Abd-alrazaq AA, Bewick BM, Farragher T, Gardner P. Factors that affect the use of electronic personal health records among patients: a systematic review. Int J Med Inform. 2019:126:164-75.

3. Archer N, Fevrier-Thomas U, Lokker C, McKibbon KA, Straus SE. Personal health records: a scoping review. J Am Med Inform Assoc. 2011;18(4):515-22.

4. Woollen J, Prey J, Wilcox L, Sackeim A, Restaino S, Raza ST, Bakken S, Feiner S, Hripcsak G, Vawdrey D. Patient experiences using an inpatient personal health record. Appl Clin Inform. 2016:7(2):446-60.

5. Bouri N, Ravi S. Going mobile: how mobile personal health records can improve health care during emergencies. JMIR Mhealth Uhealth. 2014;2(1):e8.

6. Park YR, Lee Y, Kim JY, Kim J, Kim HR, Kim YH, Kim WS, Lee JH. Managing patient-generated health data through mobile personal health records: analysis of usage data. JMIR Mhealth Uhealth. 2018;6(4):e89.

7. Wyatt J, Hoogewerf J, Quinn N, Williams J, Clement C, Thimbleby H, Sathanandam S, Rastall P. Personal health record user insights: final report. London: Royal College of Physicians; 2017.

8. The Office of the National Coordinator for Health Information Technology (ONC). What is a personal health record? 2016. https://www.healthit.gov/ providers-professionals/faqs/what-personal-health-record. Accessed 20 August 2020.

9. Vance B, Tomblin B, Studeny J, Coustasse A. Benefits and barriers for adoption of personal health records. In: 2015 Business and Health Administration Association Annual Conference at Chicago, IL; 2015.

10. Peacock S, Reddy A, Leveille SG, Walker J, Payne TH, Oster NV, Elmore JG. Patient portals and personal health information online: perception, access, and use by US adults. J Am Med Inform Assoc. 2017;24(1):e173-7.

11. Zhao JY, Song B, Anand E, Schwartz D, Panesar M, Jackson GP, Elkin PL. Barriers, facilitators, and solutions to optimal patient portal and personal health record use: a systematic review of the literature. AMIA Annu Symp Proc. 2018;2017:1913-22.

12. Perzynski AT, Roach MJ, Shick S, Callahan B, Gunzler D, Cebul R, Kaelber DC, Huml A, Thornton JD, Einstadter D. Patient portals and broadband internet inequality. J Am Med Inform Assoc. 2017;24(5):927-32.

13. Song YJ. The South Korean health care system. Jpn Med Assoc J. 2009;52(3):206-9.

14. Jung $M$, Lee $\mathrm{KH}$, Choi M. Perceived service quality among outpatients visiting hospitals and clinics and their willingness to re-utilize the same medical institutions. J Prev Med Public Health. 2009;42(3):151-9. https:// doi.org/10.3961/jpmph.2009.42.3.151.

15. Ock M, Kim JE, Jo MW, Lee HJ, Kim HJ, Lee JY. Perceptions of primary care in Korea: a comparison of patient and physician focus group discussions. BMC Fam Pract. 2014;31(15):178. https://doi.org/10.1186/ s12875-014-0178-5.
16. Bornstein BH, Marcus D, Cassidy W. Choosing a doctor: an exploratory study of factors influencing patients' choice of a primary care doctor. J Eval Clin Pract. 2000;6(3):255-62. https://doi.org/10.1046/j.1365-2753. 2000.00256.x.

17. Cheraghi-Sohi S, Hole AR, Mead N, McDonald R, Whalley D, Bower P, Roland M. What patients want from primary care consultations: a discrete choice experiment to identify patients' priorities. Ann Fam Med. 2008;6(2):107-15. https://doi.org/10.1370/afm.816.

18. Kim K, Ahn S, Lee B, Lee K, Yoo S, Lee K, Suh DH, No JH, Kim YB. Factors associated with patients' choice of physician in the Korean population: database analyses of a tertiary hospital. PLOS ONE. 2018;13(1): e0190472. https://doi.org/10.1371/journal.pone.0190472.PMID:29293 614;PMCID:PMC5749849.

19. Price M, Bellwood P, Kitson N, Davies I, Weber J, Lau F. Conditions potentially sensitive to a personal health record (PHR) intervention, a systematic review. BMC Med Inform Decis Mak. 2015;15:32.

20. Park Y, Yoon HJ. Understanding personal health record and facilitating its market. Healthc Inform Res. 2020;26(3):248-50.

21. Henderson J. Research in health information management: an expanding field of enquiry. Health Inf Manag J. 2017:46(3):103-4.

22. Wells S, Rozenblum R, Park A, Dunn M, Bates DW. Organizational strategies for promoting patient and provider uptake of personal health records. J Am Med Inform Assoc. 2015;22(1):213-22.

23. Institute of Medicine (US) Committee on Quality of Health Care in America. To Err is Human: Building a Safer Health System. Kohn LT, Corrigan JM, Donaldson MS, editors. Washington (DC): National Academies Press (US); 2000

24. Hughes RG. Tools and Strategies for Quality Improvement and Patient Safety. In: Hughes RG, editor. Patient Safety and Quality: An EvidenceBased Handbook for Nurses. Rockville (MD): Agency for Healthcare Research and Quality (US); 2008 Chapter 44.

25. Feldman SS, Buchalter S, Hayes LW. Health information technology in healthcare quality and patient safety: literature review. JMIR Med Inform. 2018;6(2):e10264. https://doi.org/10.2196/10264. Erratum in: JMIR Med Inform. 2019;7(1):e11320.

26. Alotaibi YK, Federico F. The impact of health information technology on patient safety. Saudi Med J. 2017;38(12):1173-80. https://doi.org/10 15537/smj.2017.12.20631.PMID:29209664;PMCID:PMC5787626.

27. Menachemi N, Chukmaitov A, Saunders C, Brooks RG. Hospital quality of care: does information technology matter? The relationship between information technology adoption and quality of care. Health Care Manage Rev. 2008:33(1):51-9.

28. Symons JD, Ashrafian H, Dunscombe R, Darzi A. From EHR to PHR: let's get the record straight. BMJ Open. 2019;9:e029582.

29. Lee YT, Park YT, Park JS, Yi BK. Association between electronic medical record system adoption and healthcare information technology infrastructure. Healthc Inform Res. 2018:24(4):327-34

30. Detmer D, Bloomrosen M, Raymond B, Tang P. Integrated personal health records: transformative tools for consumer-centric care. BMC Med Inform Decis Mak. 2008;8:45.

31. Assadi V, Hassanein K. Consumer adoption of personal health record systems: a self-determination theory perspective. J Med Internet Res. 2017;19(7):e270

32. Taha J, Czaja SJ, Sharit J, Morrow DG. Factors affecting usage of a personal health record (PHR) to manage health. Psychol Aging. 2013;28(4):1124-39.

33. Day K, Gu Y. Influencing factors for adopting personal health record (PHR). Stud Health Technol Inform. 2012;178:39-44.

34. Lee G, Park JY, Shin SY, Hwang JS, Ryu HJ, Lee JH, Bates DW. Which users should be the focus of mobile personal health records? Analysis of user characteristics influencing usage of a tethered mobile personal health record. Telemed J E Health. 2016;22(5):419-28.

35. Jung SY, Kim JW, Hwang H, Lee K, Baek RM, Lee HY, Yoo S, Song W, Han JS. Development of comprehensive personal health records integrating patient-generated health data directly from Samsung s-health and apple health apps: retrospective cross-sectional observational study. JMIR Mhealth Uhealth. 2019;7(5):e12691.

36. Choi BK, Park YT, Kwon LS, Kim YS. Analysis of platforms and functions of mobile-based personal health record systems. Healthc Inform Res. 2020;26(4):311-20. 
37. Luxon L. Infrastructure: the key to healthcare improvement. Future Hosp J. 2015;2(1):4-7.

38. Kruse CS, Kothman K, Anerobi K, Abanaka L. Adoption factor of the electronic heath record: a systematic review. JMIR Med Inform. 2016;4(2):e19.

39. Jamoom E, Beatty P, Bercovitz A, Woodwell D, Palso K, Rechtsteiner E. Physician adoption of electronic health record systems: United States, 2011. NCHS Data Brief. 2012;98:1-8.

40. Lupiáñez-Villanueva F, Devaux A, Valverde-Albacete J, Folkvord F, Fauli C, Altenhofer $\mathrm{M}$, et al. Benchmarking deployment of eHealth among general practitioners. Publications Office of the European Union; 2018.
41. Hersh W, Wright A. What workforce is needed to implement the health information technology agenda? Analysis from the HIMSS analytics database. AMIA Annu Symp Proc. 2008;2008:303-7.

\section{Publisher's Note}

Springer Nature remains neutral with regard to jurisdictional claims in published maps and institutional affiliations.
Ready to submit your research? Choose BMC and benefit from:

- fast, convenient online submission

- thorough peer review by experienced researchers in your field

- rapid publication on acceptance

- support for research data, including large and complex data types

- gold Open Access which fosters wider collaboration and increased citations

- maximum visibility for your research: over $100 \mathrm{M}$ website views per year

At BMC, research is always in progress.

Learn more biomedcentral.com/submissions 